\title{
Correction to: A loss of consciousness in a teenage girl with anorexia nervosa, due to polydipsia: case report and a minireview
}

\author{
Aneta Krogulska ${ }^{1} \cdot$ Dominika Nowicka $^{2} \cdot$ Zbigniew Nowicki $^{2} \cdot$ Monika Parzęcka $^{3} \cdot$ Agnieszka Sakson-Słomińska $^{1}$. \\ Renata Kuczyńska ${ }^{1}$
}

Published online: 23 April 2019

(c) Springer Nature Switzerland AG 2019

\section{Correction to: \\ Eating and Weight Disorders - Studies on Anorexia, Bulimia and Obesity https://doi.org/10.1007/s40519-018-00636-x}

Unfortunately, the published original article did not contain the open access text.

The original article has been updated.

Publisher's Note Springer Nature remains neutral with regard to jurisdictional claims in published maps and institutional affiliations.

The original article can be found online at https://doi.org/10.1007/ s40519-018-00636-x.

Aneta Krogulska anetkrog@ poczta.onet.pl

1 Department of Pediatrics, Allergology and Gastroenterology, Collegium Medicum Bydgoszcz, Nicolaus Copernicus University of Torun, M. Curie Skłodowskiej 9, 85-094 Bydgoszcz, Poland

2 Student gastroenterological research group, Department of Pediatrics, Allergology and Gastroenterology, Collegium Medicum Bydgoszcz, Nicolaus Copernicus University of Toruń, Bydgoszcz, Poland

3 Department of Pediatric Endoscopy and Gastrointestinal Function Testing, Collegium Medicum Bydgoszcz, Nicolaus Copernicus University of Toruń, Bydgoszcz, Poland 